\title{
Empirical Testing of Destination Attribute Preferences of Women Snow-sport Tourists Along a Trajectory of Participation
}

\author{
Mona Mirehie \& H. Gibson
}

\begin{abstract}
This study explored women snow-sport tourists' destination attribute preferences in relation to their participation level (e.g. skill; sport career stage) through a complementary sequential mixed-methods approach. Initially, a model illustrating a trajectory of snow-sport participation, travel behaviour and preferences was created through qualitative methods. This paper presents the quantitative testing of this proposed trajectory model and the associated destination attribute preferences. Enduring Involvement was used to quantitatively assess proposed stages of the snow-sport participation trajectory. Exploratory Factor Analysis revealed two dimensions in women's enduring involvement in snow-sports: 'identity/centrality' and 'hedonism.' Additionally, three dimensions were found for destination attributes: 'resort amenities and activities,' 'snow-sport conditions and quality,' and 'price.' A Multivariate Analysis of Variance showed that stages of the trajectory could be quantitatively verified. Analysis of Variance indicated that the importance placed on 'resort amenities and activities' decreased as women progressed along the trajectory. 'Snow-sport conditions and quality' was rated higher by more advanced skiers/snowboarders. 'Price' was rated highly along the trajectory stages.
\end{abstract}

Keywords: destination attributes; enduring involvement; women; snow-sports tourism

This is the authors' version of the work published in final form as:

Mirehie, M., \& Gibson, H. (2020). Empirical testing of destination attribute preferences of women snow-sport tourists along a trajectory of participation. Tourism Recreation Research, $0(0), 1-13$. https://doi.org/10.1080/02508281.2020.1756098 


\section{Introduction}

Snow-sports comprise a significant portion of the active sport tourism market within the U.S. However, over the past decade, there has been a considerable decline in the number of visits to ski resorts. Various factors such as climate and demographic change have been suggested as contributing to this decline (The Economist, 2018), with millennials being less likely to participate in more expensive forms of active sport tourism such as ski trips (Webber \& Record, 2017). In the U.S., the number of active skiers and snowboarders declined by about two million from the 2010-2011 to 2017-2018 season which can partially explain the decline in the number of visits by seven million in the same period of time (National Ski Areas Association, 2019). While the number of female snow-sport tourists has always been smaller in proportion to their male counterparts, most of the snow-sport dropouts are also women (Snowsports Industries America [SIA], 2016). Indeed, academic research shows that snow-sports are not only a masculine domain (Sisjord, 2013), but women report encountering more constraints preventing them from participating in snow-sport tourism when compared to men (Williams \& Lattey, 1994). Constraints such as time, hassle, and fatigue were reported (Hudson, 2000). The traditional focus on constraints provides some insights on women's participation and to some extent explains the lower rates of participation and larger number of dropouts. However, such an approach falls short in providing an understanding of what can be done to attract more female participants, prevent dropout, and facilitate continued participation and its associated tourism. Delving into the behaviour and preferences of serious skiers/snowboarders who manage to negotiate constraints and secure their long-term participation can provide insights that may help to address the limited and still declining rates of participation among women. Such knowledge is 
particularly important to mountain destinations where their tourism product is largely centered on snow-sports during the winter season.

Research shows that people who are engaged in tourism/sport activities over the longterm develop patterns of participation that resemble a career that involves changes and progress over time. Different developmental models have been created to explain these participation patterns including the Active Sport Event Travel Career (ASETC), (Buning \& Gibson, 2015) and the Travel career ladder/pattern, (Pearce, 1988; Pearce \& Lee, 2005). Certain sociological and psychological processes underpin developmental approaches to participation (Funk \& James, 2001), whereby participation at different levels is associated with certain attitudes and behaviours, and in turn involves certain needs and preferences regarding activities and places. More specifically, research has shown that skill level (clearly linked to duration and seriousness of participation) is related to frequency and length of trips which also impacts the level of importance placed on destination attributes (Richards, 1996). Despite the importance of skill level in shaping active sport tourists' destination choice preferences, little attention has been paid to this topic. Exceptions to this include McGhee, Yoon, and Cardenas's (2003) study about recreational runners' level of involvement and their travel behaviour; Buning and Gibson's (2016) study of event cycle tourists, as well as two European studies (Steen Jacobsen, Denstadli, \& Rideng, 2009; Richards, 1996) that were conducted on mixed-gender samples and both operationalized level of expertise as 'beginner, intermediate, and advanced' without looking into other aspects of long-term involvement that impact individuals' behaviour and preferences. Despite the potential significance of the female market to snow-sport tourism as yet researchers have not focused on the development of snow-sports participation trajectories among women, and their travel preferences at different participation stages. The purpose of this study was to 
address this gap in tourism research by investigating women's participation in snow-sport tourism and their destination attribute preferences in relation to their level of involvement. A complementary sequential mixed-methods approach was used to develop a conceptual framework through qualitative methods. The created framework was subsequently tested with a larger sample through quantitative methods. The quantitative testing of the framework is reported in this paper.

\section{Literature review}

\section{Career trajectories and enduring involvement}

The notion of career development is nothing new in tourism and sport studies (e.g., Travel Career Ladder/ Pattern (Pearce, 1988; Pearce \& Lee, 2005); ASETC (Buning \& Gibson, 2015); Psychological Continuum Model (PCM) (Funk \& James, 2001). A related concept that has been widely used to assess the characteristics and behaviours associated with different levels of participation is enduring involvement (EI). Bryan (1977) was the first scholar who utilized the concept of involvement in leisure research to develop the Recreation Specialization Framework that presents "a continuum of behaviour from the general to the particular, reflected by equipment and skills used in the sport and activity setting preferences" (p. 175). In this regard, involvement with an activity is indicated by equipment ownership, skill level, and centrality of the activity to an individual's life. Later, McIntyre (1989) proposed the concept of EI in relation to the place of leisure in individuals' lives and considered it as a point where an activity becomes central to a person's life. Therefore, individuals with stronger social and psychological connections to an activity engage in more behaviours associated with the activity. Research has shown empirical evidence for this among sport participants. Bryan (1977) found that more specialized anglers were more likely to choose destinations where they could fish in a novel 
destination while on vacation. Chang and Gibson (2011) similarly found in a study of paddlers that involvement level in kayaking influenced paddler's tourism choices. Those with a high level of involvement in paddling were more likely to paddle on their vacations. Beaton, Funk, Ridinger, and Jordan (2011) recommended using the involvement profiles as a tool for theoretically grouping respondents within stage-based frameworks. An example of this is Funk and James's (2001) PCM that suggests individuals' connection to a particular activity is the result of a combination of sociological and psychological processes that shape attitudes and bring about change throughout time. The authors further suggested the construct of involvement is a practical tool for differentiating the stages. Later, Beaton, Funk, and Alexandris (2009) tested dimensions of involvement on the PCM across two different samples (i.e., competitive rugby players and recreational skiers) and found that participants participation stage can be classified based according to facets of involvement.

Since its initial inception, EI has been widely used in recreation, sport, and tourism studies. Different scales have been developed to measure it (e.g., Havitz \& Dimanche, 1999; Kim, Scott, Crompton, 1997; McIntyre, 1989). Almost all items in these scales were adapted from Laurent and Kapferer's (1985) multidimensional Consumer Involvement Profile (CIP) scale that included measures of risk probability, interest, sign, risk importance, and pleasure. McIntyre's (1989) EI scale was a modification of the CIP that included three dimensions: 1) attraction - the degree to which an individual is attached to an activity, 2) self-expression - how individuals personally or socially identify themselves through an activity, and 3) centrality - how individual's lives and social connections are planned around an activity. The most prominent aspects of involvement were found to be enjoyment, centrality to life, and social bonds (McIntyre, 1989). In the context of active sport tourism, Chang (2009) adopted and adapted 
items from previous studies to develop one of the most advanced scales to measure EI. Her scale contained five dimensions: 1) Hedonic that included three items measuring satisfaction (Kyle, Absher, Norman, Hammitt, \& Jodice, 2007) pleasure, and enjoyment (Gahwiler \& Havitz, 1998);

2) Central that included six items measuring interest (Laurent \& Kapferer, 1985), commitment (Kim et al., 1997), position involvement (Pritchard, Havitz, \& Howard, 1999), and centrality (Kyle, Graefe, Manning, \& Bacon, 2004); 3) Social included two items taken from Gahwiler and Havitz (1998); 4) Self-identity included four items adopted from Kyle et al.'s sign dimension and Gahwiler and Havitz's self-expression dimension; and finally 5) the Risk dimension included four items measuring risk consequences and risk probability as suggested by Gahwiler and Havitz. After extensive tests of reliability and validity, a revised scale was developed that included five dimensions: hedonic, central, social, self-identity, and social identity (Chang, 2009). These five dimensions were present in experiences of women who were interviewed in the first phase of this study and therefore this scale was adapted to quantitatively test the framework created in the first phase.

\section{Snow-sport destinations: market segments, attribute preferences, and skilled consumption}

Over the years, researchers have used various approaches to study touristic choices and preferences of snow-sport tourists (e.g., Hudson, 2004). Segmenting the market to identify homogenous groups based upon skill levels and other criteria has been a popular approach in investigating preferred ski destination attributes. For instance, Konu, Laukkanen, and Komppula (2011) recognized six segments of ski resort visitors including all-but downhill skiing sport seekers, cross-country skiers, passive tourists, relaxation seekers, and want-it-all. This segmentation was based on four dimensions of preferred ski destination including cross-country skiing services, spa services, downhill skiing services, and restaurants and social life. Priporas, 
Vassiliadis, Bellou, and Andronikidis (2015) used leisure constraints to segment winter sport tourists. They identified five segments that were significantly different in terms of constraints and behaviour; winter sports enjoyers, least constrained, friends and family constrained, financially/cost-related constrained, and overall constrained tourists. Not surprisingly, the least constrained segment (i.e., those who negotiated the constraints better than other segments) had the greatest number of visits, longest length of stay, higher income, and higher education. Interestingly, the proportion of men and women in this segment was about equal.

Destination image has also been widely used as another tool to examine different aspects of snow-sport destination. For example, Papadimitriou and Gibson (2008) identified three dimensions that represented destination image for active snow-sport tourists: attractions, environment, and outdoor activity suitability. Similarly, Hallmann, Zehrer, and Muller (2013) developed a model of winter sports destination image and assessed its influence on tourists' revisit intention. The authors concluded that both affective and cognitive elements of destination image are important in assessing experiences of tourists and their revisit intention. However, the cognitive aspect was more significant than the affective aspect.

Another approach to investigating different destination preferences is the concept of skilled consumption. Skilled consumption is rooted in consumer behaviour research and is similar to recreation specialization (Bryan, 1977) in that depending on their level of proficiency with using a product/service, consumers use different criteria to evaluate attributes of a product/service and make purchase decisions (e.g., Brucks, 1985; Jacoby, Troutman, Kuss, \& Mazursky, 1986). Participation in active sport tourism is a form of skilled consumption since tourists with differing levels of knowledge and skill consider different destination attributes when choosing a destination (Buning \& Gibson, 2016; Richards, 1996). 
Closely related to this study, Won, Bang and Shonk (2008) used a consumption situation and recreation specialization to segment college student skiers/snowboarders and explore their ski destination choices in relation to aspects of recreation specialization. The authors found that knowledge and skill were positively related to preference for trail variety. There were also positive relationships between snow condition, years and frequency of participation with more frequent and longer length of participation. In the same vein, Hungenberg, Gould, and Daly (2013) applied a serious leisure approach to investigate skiers' skill level, frequency of participation, and spending behaviour. The authors found that the level of seriousness significantly determined the frequency of participation. They argued that once individuals build an identity based on a leisure activity such as skiing, they dedicate more time and energy to develop the respective skill set so that they retain their identity. Also, the more serious skiers appeared to be more willing to spend money on ski-related products/activities.

Although the existing literature provides insights about different elements of snow-sport trips and tourist experiences, so far, only two studies have considered the destination attribute preferences of snow-sport tourists in relation to their skill level. Richards (1996) found that advanced skiers take more ski vacations and their ski trips are longer. In terms of destination choice, advanced skiers select a destination based on sport related attributes and travel to specific areas in search of optimal ski conditions. In a secondary analysis of the winter season data from the 2000 Norwegian Foreign Visitor Survey, Jacobson et al. (2009) found that advanced skiers consider ski and facility attributes more important than the intermediate skiers while intermediate considered price as more important. Beginners were excluded from the study since the sample size was too small to run the analysis. Overall, however, little scholarly attention has been paid to long-term patterns of participation and destination attribute preferences exhibited by 
participants at different stages on a sport related trajectory and a study with a focus on female participants is particularly unique.

\section{Theoretical framework}

As mentioned before, this study is part of a larger complementary mixed-methods study. Here, a complementary design means that one method is used to extend the findings of another method (Creswell \& Plano Clark, 2007). This study consisted of a qualitative study followed by a quantitative study that examined the qualitative findings among a larger sample. In the qualitative phase, 13 semi-structured in-depth interviews were conducted with women skiers/snowboarders. Data were analysed using Charmaz's (2006) constructivist grounded theory guidelines. A framework of women's participation in active snow-sport tourism (Figure 1) was developed suggesting a trajectory of participation comprised of three main stages: initiation (lowest level of involvement; no distinguishing travel behaviour), attachment (medium level of involvement; destination and activities during the snow-sport trips are mostly determined by trip companions), commitment (highest level of involvement; increased focus on planning the snowsport trips; increased emphasis on snow-sport conditions in the destination). The interviewees spoke about their tourism preferences and the importance placed on different destination attributes and these appeared to differ at each participation stage. As such, this framework sets the theoretical foundation for the quantitative phase reported in this paper the focus of which is a quantitative investigation of the snow-sport trajectory stages and the destination attributes reported by these women. Four research questions were posed: RQ1) What are the dimensions of women's EI in snow-sports? RQ2) Does the level of EI differ across the qualitatively proposed stages of participation? RQ3) What dimensions characterise destination attributes' preferences of 
female snow-sport tourists? RQ4) Does the importance placed on the dimensions of destination attributes differ across stages of participation?

\section{Methods}

\section{Data collection}

Data were collected via an online self-administered questionnaire using Qualtrics software. To balance the number of respondents at various snow-sport participation stages within the sample, Amazon Mechanical Turk (MTurk) and snow-sport clubs were used to recruit the respondents. All the ski clubs within the US that had valid contact information listed online $(N=578)$ were contacted (480 email messages were sent, and 205 digital flyers were posted on clubs' Facebook pages) and asked to send the recruitment materials to their members and invite them to participate in the study.

Since the snow-sport club members are mostly advanced level skiers/snowboarders, MTurk was used as a complementary channel to recruit beginners and intermediate participants. MTurk respondents were delimited to women within the U.S who had experience with snowsports. MTurk respondents received $\$ 0.75$ (USD) as compensation for participating in this study. In order to decrease the chance of a survey code being shared, Qualtrics' random number generator function was used to give a unique random number to each of the participants at the completion of the survey. Survey code screening revealed no identical survey codes. No direct compensation was provided to respondents who were recruited through their club membership.

\section{Instrumentation}

The questionnaire contained five sections:

1. Skier/snowboarders' profile: to determine the place of respondents in the stages of the trajectory, four vignettes were developed based on the qualitative findings that represented 
characteristics of the skiers/snowboarders at each stage. The vignettes were labeled Type 1, Type 2, Type 3, and Type 4. Type 1 represents women at the initiation stage, Type 2 and Type 3 represent women at the attachment stage, and Type 4 represents women at the commitment stage. Content validity of the vignettes was approved by discussion with a panel of experts. Respondents were asked to read the descriptions and indicate which of the four vignettes best described them. Then EI was applied to verify the existence of these stages.

2. Enduring Involvement: Chang's (2009) 5-dimensional scale was utilized since it seemed to best fit the statements of the interviewees from the qualitative phase. The dimensions included: hedonic (four items), central (five items), social (three items), self-identity (three items), and social identity (three items). Respondents were asked to rate each of the items on a 7point Likert scale where 1 = 'strongly disagree' and 7 = 'strongly agree.'

3. Destination attributes: 11 items were adopted from Richards' (1996) study, namely: total price, ski conditions, range of slopes, accommodation price, accommodation quality, piste (trail) grooming, terrain, lift ticket price, leisure facilities, resort accessibility, and sightseeing attractions. These items appeared to represent the statements of the interviewees in the first phase of this study. Based on the qualitative findings, four items were added to the scale, namely, quality of the available food places, price of the available food places, good shopping, and opportunity for other outdoor activities. Respondents were asked to rate the importance of 15 destination attributes on a seven-point Likert scale where $1=$ 'not at all important' and $7=$ 'extremely important.'

Sections 4 and 5 consisted of ancillary items such as participation and travel patterns, and demographics. 
The survey instrument was pretested through discussion with a panel of experts and retrospective verbal probing interviews (i.e., cognitive interviews to improve the instrument design and identify potential sources of response error; Willis, 2004) with interviewees from the qualitative phase. The final version of the questionnaire was distributed after the process of revising and pretesting was concluded.

\section{Sample characteristics}

The sample consisted of women, 18 to 87 years old $(M=41.41, S D=16.10)$, who participate in skiing/snowboarding $(N=794)$. The sample was predominantly White/Caucasian $(80.3 \%, n=$ 627). The greatest number of respondents were married $(44.3 \%, n=346)$, followed by singles $(38.4 \%, n=300)$. The most commonly reported number of children was none $(53.4 \%, n=416)$, followed by two $(21.1 \%, n=164)$, one $(15.4 \%, n=120)$, and three $(7.2 \%, n=56)$. In terms of educational level, the greatest proportion of the sample had a bachelor's degree $(43.6 \%, n=$ 341). With respect to the snow-sport participation profile, more than half of the respondents were skiers $(56.7 \%, n=447)$, and one fifth were snowboarders $(20.3 \%, n=160)$. Thirteen percent of the respondents indicated that they were mainly skiers and occasionally snowboard $(13.2 \%, n=$ $104)$ and the remaining were mainly snowboarders and occasionally ski $(9.9 \%, n=78)$. Sixty four percent of the respondents did not belong to a ski/snowboard club $(n=508)$. Of those who did belong to a club $(36 \%, n=285), 21.8 \%$ were currently an officer in that club. The sample reported a mean of 15.66 years of participation $(S D=16.40$; ranged from 0 to 74 years) in skiing and 2.87 years of participation in snowboarding ( $S D=4.82$; ranged from 0 to 37 years).

Respondents reported a mean of 13.97 days of skiing/snowboarding $(S D=18.52$; ranged from 0 to 180 days $)$. The number of snow-sport areas visited varied from one to $100(M=9.83, S D=$ 11.33). 
The majority of respondents $(85.2 \%, n=672)$ reported that they travelled to ski/snowboard areas that were 50 miles away from their home. The most commonly reported length and frequency of the ski/snowboard trip was occasional 2-3 day-long trips $(37 \%, n=250)$. More than fifty percent of the respondents reported that their ski/snowboard trip partners were family $(59 \%, n=468)$, and/or friends (non-club members) $(56.2 \%, n=446)$, followed by club members $(29.3 \%, n=232)$. Only $8.7 \%$ took solo ski/snowboard trips $(n=69)$. Fifty three percent stayed in hotels $(53.8 \%, n=427)$, followed by rental house/apartment $(39 \%, n=309)$, and $25 \%$ stayed with family/friends who live close to the mountains $(n=198)$.

\section{Data analysis}

Initially, Confirmatory Factor Analysis was used to test the dimensions of EI, however, the previously identified dimensions were not verified. Therefore, to answer RQ1 and RQ3, Principal Components Analysis (PCA) was conducted. To consider all possible factor solutions the analysis was run with different rotations and alternative extraction methods for each of the scales. A maximum of 52 cases per variable for destination attributes ( 15 items), and a minimum of 44 for the EI scale (18 items) satisfied the required minimum amount of data (i.e., 5:1) as recommended by Hair, Black, Babin, and Anderson's (2010). Per Hair et al.'s (2010) suggestion, factor loadings bigger than .5 and Eigenvalues greater than one were deemed acceptable for interpreting factors. Bartlett's test of sphericity and Kaiser-Meyer-Olkin measure of sampling adequacy $(\mathrm{KMO}>.8)$ were utilized to confirm the factorability of correlation matrices.

To answer RQ2, a Multivariate Analysis of Variance (MANOVA) was conducted with four types of skiers/snowboarders as an independent variable and EI dimensions as dependent variables. To answer RQ4, one-way Analysis of Variance (ANOVA) was conducted with four 
types of skiers/snowboarders as the independent variable and destination attribute dimensions as the dependent variables.

\section{Results}

Descriptive statistics showed that $40.3 \%$ of the respondents $(n=319)$ identified as Type 4 skiers/snowboarders (i.e., commitment stage), 28.4\% were Type 2 (i.e., attachment stage) ( $n=$ 225), 19.3\% were Type 1 (i.e., initiation stage) $(n=153)$, and 12\% were Type 3 (i.e., attachment stage) $(n=95)$ (Table 1$)$. The highest rated EI item was 'skiing/snowboarding is pleasurable' $(M$ $=5.80, S D=1.47)$ followed by 'I really enjoy skiing/snowboarding' $(M=5.71, S D=1.55)$ and 'skiing/snowboarding interests me a lot' $(M=5.24, S D=1.68)$ while 'I find a lot of my life is organized around skiing/snowboarding' was the lowest rated EI item $(M=3.64, S D=2.04)$ followed by 'skiing/snowboarding is pleasurable' $(M=3.84, S D=1.97)$, and 'most of my friends or family members are in some way connected to skiing/snowboarding' $(M=3.92, S D=$ 1.88). The highest rated destination attribute was 'ski conditions' $(M=5.76, S D=1.26)$ while the lowest rated attribute was 'good shopping' $(M=3.01, S D=1.78)$. Complete descriptive statistics for EI (18 items), and destination attributes (15 items) are presented in Tables 2 and 3.

\section{RQ1) What dimensions characterise women's EI in snow-sports?}

Four items were dropped out of the analysis because of cross-loadings; namely, 'I enjoy discussing skiing/snowboarding with my friends or family,' 'participation in skiing/snowboarding says somethings about me,' 'participating in skiing and snowboarding is one of the most satisfying things I do,' and 'skiing/snowboarding reflects my lifestyle.' The remainder of the items loaded on two factors that cumulatively explained $73 \%$ of the total variance. The factors were labeled as 'identity/centrality' $(\alpha=.95, M=4.03)$, and 'hedonism' $(\alpha$ $=.86, M=1.35)$ (Table 4). Since this finding was different from previous research where EI was 
found to have either three (e.g., Chang \& Gibson, 2015; McIntyre, 1989) or five dimensions (e.g., Chang, 2009), the analysis was rerun by fixing the number of the factors first on 5 and then on 3 which, in both cases, resulted in Eigen values lower than one for all factors except for the first two. Therefore, the two initially identified factors were retained and utilized in the following steps of the analysis.

\section{RQ2) Does the level of EI differ across stages of participation?}

A one-way between group MANOVA revealed a statistically significant multivariate effect between the grouping variable 'types of skiers/snowboarders' and the dependent variables 'identity/centrality' and 'hedonism' which were the two dimensions of the EI identified through EFA; Pillai's Trace $=.43, F(6,1576)=72.041, p<.05$. Since the group sizes for the four types of skiers/snowboarders were unequal, Pillai's criterion was used which is considered more robust in this situation (see Hair et al., 2010). Also, there were significant between group differences for each of the dependent variables and the grouping variable (Table 5). Bonferroni post hoc analysis showed that there was a significant increase in 'identity/centrality' from Type 1 to Type 4 (Type $1<$ Type $2<$ Type $3<$ Type 4 ) at $p<.05$. Likewise, 'hedonism' increased from Type 1 to Type 4 (Type $1<$ Type $2<$ Type $3<$ Type 4 ) at $p<.05$, however, the mean difference between Type 2 and Type 3 for hedonism was not statistically significant (Table 6).

\section{RQ3) What dimensions characterise destination attributes preferences of female snow-sport}

\section{tourists?}

Two items cross-loaded on three factors and therefore were dropped out of the analysis; namely, 'accommodation quality', and 'resort accessibility'. The other thirteen items loaded on three factors that cumulatively explained $66.47 \%$ of the total variance. The factors were labeled as 'resort amenities and activities' $(\alpha=.86, M=3.86)$, 'snow sport conditions and quality' $(\alpha=.81$, 
$M=5.43)$, and 'price' $(\alpha=.83, M=5.41)$. Regarding reliability, all factors exceeded the acceptable level of internal consistency (i.e., Cronbach's alpha $>.7$ ) as suggested by Nunnelly (1978). In terms of convergent validity all factors exceeded agreed upon level of average variance extracted (i.e., AVE > .5) (Table 7).

\section{RQ4) Does the importance placed on the dimensions of destination attributes differ across} stages of participation?

Three one-way ANOVAs were conducted to assess whether the identified dimensions of the destination attributes (i.e., resort amenities and activities, snow-sport conditions and quality, price) were rated differently by the four types of skiers/snowboarders. Interestingly, Type 1 (initiation) had the highest mean rating for 'resort amenities and activities' $(M=4.29, S D=1.3)$, followed by Type $2(M=4.27, S D=1.33)$, Type $3(M=3.87, S D=1.42)$, and Type $4(M=3.51$, $S D=1.23)$. ANOVA showed four types of skiers/snowboarders differed significantly in how they rated the importance of 'resort amenities and activities' $F(3,548)=13.26, p<.05$. Bonferroni pairwise comparisons showed the importance placed on 'resort amenities and activities' decreased from Type 1 to Type 4 (Type $1>$ Type $2>$ Type $3>$ Type 4 ). However, the differences were statistically significant only between Type 1 and Type $4(p=.000)$; and Type 2 and Type $4(p=.000)$.

The four types of skiers/snowboarders were relatively homogeneous in how they rated the importance of 'snow-sport conditions and quality,' but Type 4 had the highest mean rating for this dimension (Type 1, $M=4.97, S D=1.34$; Type 2, $M=5.40, S D=1.09$; Type 3, $M=$ $5.37, S D=1.02$; Type $4, M=5.64, S D=1.00$ ). ANOVA revealed that mean ratings were significantly different across the four groups $F(3,547)=7.79, p<.05$. However, not all the 
mean differences were statistically significant. Bonferroni post hoc analysis showed significant differences between Type 1 and Type $2(p=.012)$, as well as Type 1 and Type $4(p=.000)$. The 'price' dimension was rated highly by all four types of skiers/snowboarders (Type 1, $M=$ $5.55, S D=1.17$; Type 2, $M=5.48, S D=1.28$; Type 3, $M=5.37, S D=1.02$; Type 4, $M=5.64$, $S D=1.00)$. The mean ratings of this dimension were not statistically significantly different across the four types of skiers/snowboarders (Tables $8 \& 9$ ).

\section{Discussion}

The purpose of this study was investigating women's trajectory of participation in snow-sport tourism and their destination attribute preferences in relation to their level of involvement in snow-sports. First, in relation to testing the construct validity of the EI scale, in contrast to other studies where EI typically has either three (e.g., Kyle et al., 2004, McIntyre, 1989; Chang \& Gibson, 2015) or five dimensions (e.g., Chang, 2009, 2014; Chang, Gibson, \& Sisson, 2013), our analysis revealed two dimensions for EI. CFA did not validate the previously identified EI dimensions; neither did exploratory factor analysis (EFA) with a fixed number of factors (i.e., 3 and 5). Perhaps, EI dimensions that have been commonly used in recreation, leisure, and tourism research are not persistent yet and further research is needed to examine the dimensions within different contexts. More specifically, since the current study focused on women the findings may be an indication of sensitivity of the EI dimensions to gender as first suggested by Wiley, Shaw and Havitz (2000). Wiley et al.'s analysis showed that men and women differed in terms of dimensions of their involvement with sport. While attraction was more notable for women, centrality was more important for men. More research is needed to further investigate this sensitivity to gender and also to assess such sensitivity to other variables. 
Regarding the first research question that asked which of the EI dimensions were related to women's trajectory of participation in snow-sports, the mean ratings of the two identified EI dimensions (i.e., identity/centrality, hedonism) supported the theoretical propositions of the qualitative phase of this study. Type 1 (initiation stage) skiers/snowboarders were the lowinvolvement group with mean ratings below the mid-point of the scale on the identity/centrality dimension of EI. Type 2 and Type 3 (attachment stage) were the medium-involvement group with mean identity/centrality ratings about the mid-point of the scale. Type 4 (commitment stage) was the high-involvement group whose mean rating on the identity/centrality was above the mid-point of the scale. This reflects and reinforces the findings in the qualitative phase of this study and aligns with propositions regarding the necessity of a certain level of skill and knowledge for individuals to identify more strongly with an activity or setting (Fendt, 2015). This high level of knowledge and skill is not acquired unless involvement endures over time, which typically takes individuals along a leisure career. In this study, once women attain the commitment stage, they have enough skill, experience, and social connections to form self- and social-identity in relation to snow-sports which also makes the activity central to their lives. Such identity formation through sport participation has been discussed in feminist research (e.g., Kleiber \& Kane, 1984). The empowering aspects of women's engagement in leisure particularly in male dominated activities has also been discussed (Henderson, 1996). Accordingly, one reason for women's initial involvement in sport and pursuing it to the highest level could be the opportunities that sport provides for physical and mental challenge (Shaw, Kleiber, \& Caldwell, 1995) which help women to push through the traditionally ascribed gender roles and form alternative identities (Kleiber \& Kane, 1984). An example of this in the context of snow-sports was Spowart, Hughson and Shaw's (2008) study in which they found mothers used 
snowboarding as a way to form identities beyond being a mother. In this study, the construction of new identities as skiers/snowboarders could be a confirmation of previous research regarding empowerment through leisure. Identity construction also relates to the women's broad social network around snow-sports in the commitment stage and the support they receive from significant others, both partners and friends. Research has shown that individuals' perceptions of how others see them are important in building and retaining leisure behaviour and identities (Cast, 2003 as cited in Jun \& Kyle, 2012). In fact, Jun et al. (2012) found that identity was an antecedent of other dimensions of EI.

The mean rating for the hedonism dimension was above the mid-point of the scale for all three stages which mirrored the high hedonic (i.e., positive affects) value of participation in snow-sport tourism (Hallman, Feiler, Muller \& Breuer, 2012). Although all three stages had high hedonic ratings, there was a significant increase from initiation to attachment and then to commitment. While the mean rating of hedonism increased from Type 2 to Type 3 , the difference was not statistically significant. However, this does not impact the staging categorization because Type 2 and Type 3 are both in the attachment stage. Mean hedonism in the commitment stage was significantly higher than both attachment and initiation which may relate to various factors such as the skillfulness of women at this stage and their broad social network around snow-sports.

High emphasis on the sport and participating for the sake of sport itself was one characteristic of the commitment stage. Hence, the increasing hedonic value may relate to the concept of flow and a full immersion that highly involved women in this stage experience. Havitz and Mannell (2005) previously noted that high levels of involvement in an activity results in flow or an optimal experience. Csikszentmihalyi (1990) defined flow as "the state in which 
people are so involved in an activity that nothing else seems to matter. The experience itself is so enjoyable that people will do it even at great cost, for the sheer sake of doing it" (p. 4). This state of mind/body, which necessitates an optimal balance between challenge and skill, results in happiness that is generated by the individual rather than the environment (Csikszentmihalyi, 1990). Snow-sports require a lot of effort for developing skill and overcoming fear of injury, altitude, speed, cold weather. Therefore, women in the primary stages of a career-trajectory are less likely to experience flow since they have not achieved the optimal equilibrium between skill and challenge yet. This justifies the increase in hedonism from initiation to attachment and to commitment where women experience the best moments which "usually occur when a person's body or mind is stretched to its limits in a voluntary effort to accomplish something difficult and worthwhile" (Csikszentmihalyi, 1990, p. 173).

These findings provided evidence that the proposed framework can be empirically verified. The level of EI increased from Type 1 to Type 4 skiers/snowboarders which suggests as the psychological connection to an activity becomes stronger, individuals engage in more behaviour relevant to that activity (Beaton et al., 2011). This supports previously created developmental models of participation (e.g., ASETC Buning \& Gibson, 2015; PCM Funk \& James, 2001; Serious Leisure Stebbins, 1992) in that individuals participate in an activity at various levels and each level is associated with different social, psychological, and behavioural processes. This not only expands the qualitative findings, but also provides a measurable framework that can be used in future research and provides further support for applicability of the concept of EI in classifying participants into theoretically developed stages of engagement in an activity (Beaton et al., 2011) which subsequently helps in distinguishing behaviours and attitudes of participants (Beaton et al, 2009). However, despite the significant difference in 
hedonism among the three stages, the clear low, medium, and high identity/centrality divide among the groups suggests that this dimension is a more reliable tool for categorizing participants in three stages.

In terms of linking involvement level and trajectory of snow-sports among these women to destination attributes, the findings appear to confirm the patterns identified in the qualitative study. In terms of choosing a particular destination, sport-related attributes increased in prominence with higher levels of involvement and the later trajectory stages. In contrast, during the initiation stage, resort amenities and activities decreased in importance from the initiation to commitment stages. This aligns with previous research (Jacobson et al., 2009; Richards, 1996) in that advanced participants choose a destination based on snow conditions and travel to certain destinations in search of optimal skiing conditions while beginners attach more importance to other aspects of destination such as accommodation quality. Price was also rated highly by all respondents which may highlight the high cost of snow-sports and sensitivity of skiers/snowboarders of all skill and involvement levels to the participation/travel price. In fact, Williams and Basford (1992) found that cost was an important barrier to snow-sports participation. Similar to Richards' (1996) findings regarding the higher price sensitivity of the beginners, while there were not any significant differences in the importance placed on the price, skiers/snowboarders in the initiation stage were more concerned with the price when choosing a destination than those in the attachment and commitment stages. While all women considered price as an important attribute in choosing a destination, the fact that the mean rating decreased from initiation to attachment and then to commitment is evident as participation becomes more serious and participants are willing to pay higher prices in exchange for a better experience. Perhaps as they move along the trajectory, they become involved in additional aspects of snow- 
sports experience and thus would accept paying a higher price. Alternatively, as Richards (1996) contended, they may choose certain destinations because they are likely to find optimal skiing/snowboarding conditions, and this may require them to pay a higher price. Nevertheless, the fact that women at all stages placed high importance on price and the difference in ratings was not statistically significant could signify that the female market is generally more sensitive to price.

This study has various implications for snow-sports and associated resort destinations. The identified stages that demonstrate different levels of women's participation in snow-sports provide a practical segmentation tool for resorts who wish to attract more women. Different levels of importance placed on dimensions of destination attributes suggest that providing diverse facilities and services may help resorts attract women of various participation levels with various needs and preferences. Providing diverse amenities and activities in a resort may encourage more visits from women at the beginner and intermediate levels. Although price was rated highly by all women and there were no significant differences in ratings based upon the trajectory stages, beginners and intermediates appeared to be slightly more sensitive to price. Hence, offering discount prices for these women could be an effective strategy to attract them. 


\section{References}

Active Domestic Skiers/Snowboarders (2016). National Ski Areas Association. Retrieved from http://www.nsaa.org/press/industry-stats/

Beaton, A. A., Funk, D. C., \& Alexandris, K. (2009). Operationalizing a theory of participation in physically active leisure. Journal of Leisure Research, 41, 177-203.

Beaton, A. A., Funk, D. C., Ridinger, L., \& Jordan, J. (2011). Sport involvement: A conceptual and empirical analysis. Sport Management Review, 14, 126-140.

Brucks, M. (1985). The effects of product class knowledge on information search behaviour. Journal of Consumer Research, 12, 1-16.

Bryan. H. (1977). Leisure value systems and recreational specialization: The case of trout anglers. Journal of Leisure Research, 9, 174-187.

Buning, R. J., \& Gibson, H. (2015). The evolution of active-sport-event travel careers. Journal of Sport Management, 29(5), 555-569.

Buning, R. J., \& Gibson, H. J. (2016). The role of travel conditions in cycling tourism: implications for destination and event management. Journal of Sport \& Tourism, 20(3-4), 175-193.

Cast, A.D. (2003). Identities and behaviour. In P.J. Burke, T.J. Owens, R. T. Serpe \& P.A. Thoits (Eds.), Advances in identity theory and research (pp. 41-53). New York: Kluwer Academic/Plenum Publishers.

Chang, S. (2009). Relationship between active leisure and active vacations (Doctoral dissertation). Retrieved from http://etd.fcla.edu/UF/UFE0024249/chang_s.pdf (ufl.022863495). 
Chang, S., \& Gibson, H. J. (2011). Physically active leisure and tourism connection: Leisure involvement and choice of tourism activities among paddlers. Leisure Sciences, 33, 162181.

Chang, S., Gibson, H., \& Sisson, L. (2014). The loyalty process of residents and tourists in the festival context. Current Issues in Tourism, 17(9), 783-799.

Charmaz, K. (2006). Constructing grounded theory: A practical guide through qualitative research. London: Sage Publications.

Creswell, J. W., \& Clark, V. L. P. (2007). Designing and conducting mixed methods research. Csikszentmihalyi, M. (1990). Flow, the psychology of optimal experience. New York, NY: Harper \& Row.

Fendt, L. S. (2015). What is it like to be a surfer girl: a phenomenological exploration of women's surfing (Doctoral dissertation). Retrieved from https://epubs.scu.edu.au/cgi/viewcontent.cgi? article=1455\&context=theses.

Gahwiler, P., \& Havitz, M. E. (1998). Toward a relational understanding of leisure social worlds, involvement, psychological commitment, and behavioural loyalty. Leisure Sciences, 20, $1-23$.

Hair, J. F. J., Black, W. C., Babin, B. J., \& Anderson, R. E. (2010). Multivariate data analysis ( $7^{\text {th }}$ ed.). Upper Saddle River, NJ: Pearson Prentice Hall.

Hallmann, K., Feiler, S., Müller, S., \& Breuer, C. (2012). The interrelationship between sport activities and the perceived winter sport experience. Journal of Sport \& Tourism, 17, $145-163$. 
Hallmann, K., Zehrer, A., \& Müller, S. (2013). Perceived destination image: An image model for a winter sports destination and its effect on intention to revisit. Journal of Travel Research, 54, 94-106.

Havitz, M. E., \& Dimanche, F. (1999). Leisure involvement revisited: Drive properties and paradoxes. Journal of Leisure Research, 31, 122-149.

Havitz, M.E., \& Mannell, R.C. (2005). Enduring involvement, situational involvement, and flow in leisure and on-leisure activities. Journal of Leisure Research, 37, 152-177.

Henderson, K. A. (1996). One size doesn't fit all: The meanings of women's leisure. Journal of Leisure Research, 28(3), 139-154.

Hudson, S. (2000). The segmentation of potential tourists: Constraint differences between men and women. Journal of Travel Research, 38, 363-368.

Hungenberg, E., Gould, J., \& Daly, S. (2013). An examination of social psychological factors predicting skiers' skill, participation frequency, and spending behaviours. Journal of Sport \& Tourism, 18, 313-336.

Funk, D. C., \& James, J. (2001). The psychological continuum model: A conceptual framework for understanding an individual's psychological connection to sport. Sport management review, 4(2), 119-150.

Jacoby, J., Troutman, T., Kuss, A., \& Mazursky, D. (1986). Experience and expertise in complex decision making. Advances in Consumer Research, 13(1), 469-472.

Jun, J., \& Kyle, G. T. (2012). Gender identity, leisure identity, and leisure participation. Journal of Leisure Research, 44(3), 353-378. 
Jun, J., Kyle, G. T., Vlachopoulos, S. P., Theodorakis, N. D., Absher, J. D., \& Hammitt, W. E. (2012). Reassessing the structure of enduring leisure involvement. Leisure Sciences, 34(1), 1-18.

Kim, S. S., Scott, D., \& Crompton, J. L. (1997). An exploration of the relationships among social psychological involvement, behavioural involvement, commitment, and future intentions in the context of birdwatching. Journal of Leisure Research, 29(3), 320-341.

Kleiber, D. A., \& Kane, M. J. (1984). Sex differences and the use of leisure as adaptive potentiation. Loisir et Société/Society and Leisure, 7(1), 163-173.

Konu, H., Laukkanen, T., \& Komppula, R. (2011). Using ski destination choice criteria to segment Finnish ski resort customers. Tourism Management, 32, 1096-1105.

Kyle, G., Absher, J., Norman, W., Hammitt, W., \& Jodice, L. (2007). A modified involvement scale. Leisure studies, 26(4), 399-427.

Kyle, G., Graefe, A., Manning, R., \& Bacon, J. (2004). Predictors of behavioural loyalty among hikers along the Appalachian Trail. Leisure Sciences, 26, 99-118.

Laurent, G., \& Kapferer, J. N. (1985). Measuring consumer involvement profiles. Journal of Marketing Research, 22(1), 41-53.

McIntyre, N. (1989). The personal meaning of participation: Enduring involvement. Journal of Leisure Research, 21, 167-179.

McGehee, N. G., Yoon, Y., \& Cardenas, D. (2003). Involvement and travel for recreational runners in North Carolina. Journal of Sport Management, 17(3), 305-324.

Nunnelly, J. N. (1978). Psychometric theory (2nd ed.). New York, NY: McGraw-Hill. 
Papadimitriou, D., \& Gibson, H. (2008). Benefits sought and realized by active mountain sport tourists in Epirus, Greece: Pre-and post-trip analysis. Journal of Sport \& Tourism, 13, 3760.

Pearce, P. L. (1988). The Ulysses Factor: Evaluating Visitors in Tourist Settings. New York: Springer-Verlag.

Pearce, P. L., \& Lee, U. I. (2005). Developing the travel career approach to tourist motivation. Journal of travel research, 43(3), 226-237.

Pritchard, M. P., Havitz, M. E., \& Howard, D. R. (1999). Analyzing the commitment-loyalty link in service contexts. Journal of the Academy of Marketing Science, 27, 333-348.

Priporas, C. V., Vassiliadis, C. A., Bellou, V., \& Andronikidis, A. (2015). Exploring the constraint profile of winter sports resort tourist segments. Journal of Travel Research, 54, 659-671.

Richards, G. (1996). Skilled consumption and UK ski holidays. Tourism Management, 17, 2534.

Shaw, S. M., Kleiber, D. A., \& Caldwell, L. L. (1995). Leisure and identity formation in male and female adolescents: A preliminary examination. Journal of Leisure Research, 27, 245-263.

Sisjord, M. K. (2013). Women's snowboarding-some experiences and perceptions of competition. Leisure Studies, 32, 507-523.

Snow Sports Fact Sheet (2016). Snowsports Industries America. Retrieved from http://www.snowsports.org/research-surveys/snow-sports-fact-sheet/

Spowart, L., Hughson, J., \& Shaw, S. (2008). Snowboarding mums carve out fresh tracks: resisting traditional motherhood discourse? Annals of Leisure Research, 11, 187-204. 
Stebbins, R. A. (1992). Amateurs, professionals, and serious leisure. Buffalo, NY: McGillQueen's University Press.

Steen Jacobsen, J. K., Denstadli, J. M., \& Rideng, A. (2008). Skiers' sense of snow: tourist skills and winter holiday attribute preferences. Tourism Analysis, 13, 605-614.

The Economist (2018). Winter sports face a double threat, from climate and demographic change. Retrieved from https://www.economist.com/international/2018/01/27/wintersports-face-a-double-threat-from-climate-and-demographic-change

Webber, C., Record, P. (2017). As baby boomers leave ski slopes, millennials fail to fill gap. Retrieved from https://skifederation.org/baby-boomers-leave-ski-slopes-millennials-failfill-gap/

Williams, P. W., \& Basford, R. (1992). Segmenting downhill skiing's latent demand markets. The American Behavioural Scientist, 36, 222-235.

Williams, P. W., \& Lattey, C. (1994). Skiing constraints for women. Journal of Travel Research, 33, 21-25.

Wiley, C. G., Shaw, S. M., \& Havitz, M. E. (2000). Men's and women's involvement in sports: An examination of the gendered aspects of leisure involvement. Leisure Sciences, 22(1), 19-31.

Won, D., Bang, H., \& Shonk, D. J. (2008). Relative importance of factors involved in choosing a regional ski destination: Influence of consumption situation and recreation specialization. Journal of Sport \& Tourism, 13, 249-271. 


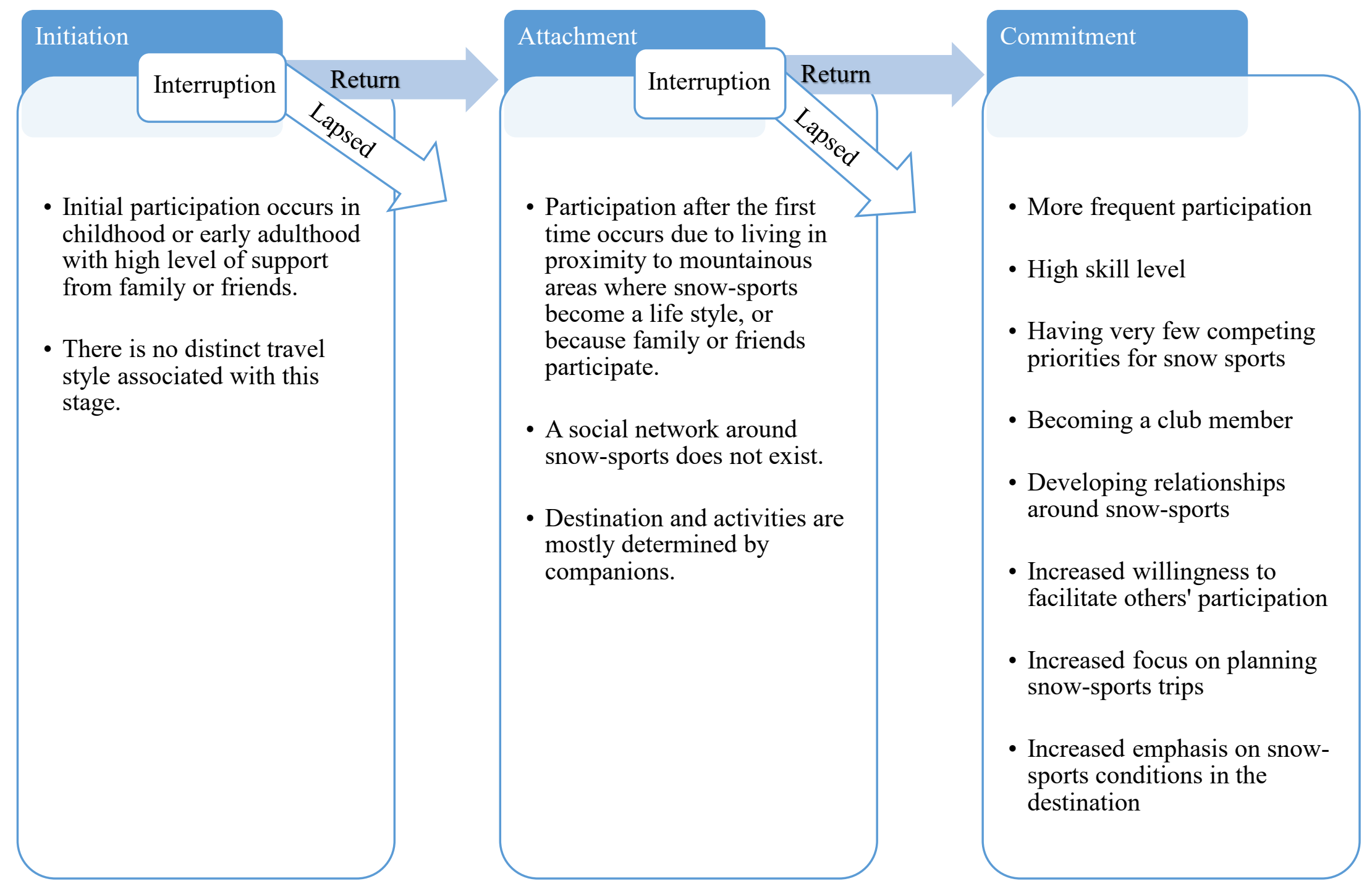

Figure 1. Proposed grounded theory of women's experiences of participation in snow-sports and destination attribute preferences 
Table 1.

Type of skier/snowboarder

\begin{tabular}{|c|c|c|}
\hline Vignettes & Frequency & Percent \\
\hline $\begin{array}{l}\text { Type } 1 \\
\text { I have skied/snowboarded once/twice in my life as family/friends } \\
\text { encouraged me to do so. I may or may not ski/snowboard again. } \\
\text { I am definitely a beginner. }\end{array}$ & 153 & 19.3 \\
\hline $\begin{array}{l}\text { Type } 2 \\
\text { I ski/snowboard occasionally because my family/friends } \\
\text { ski/snowboard. } \\
\text { Usually, I let family/friends decide about the destination and plan } \\
\text { the trip. I do not mind replacing skiing/snowboarding with another } \\
\text { activity if my family/friends find a good alternative. I am an } \\
\text { advanced beginner or intermediate skier/snowboarder. }\end{array}$ & 225 & 28.4 \\
\hline $\begin{array}{l}\text { Type } 3 \\
\text { I participate in skiing/snowboarding because I live near the } \\
\text { mountains and snow sports are convenient physical activities during } \\
\text { the winter months. I do not mind replacing skiing/snowboarding } \\
\text { with another activity if I find a good alternative or if I ever moved } \\
\text { away from the mountains. I am an intermediate skier/snowboarder. }\end{array}$ & 95 & 12.0 \\
\hline $\begin{array}{l}\text { Type } 4 \\
\text { I participate regularly. Typically, I do not miss a season of } \\
\text { skiing/snowboarding. I plan in advance to make sure I dedicate } \\
\text { money and time to skiing/snowboarding (e.g., I purchase a season } \\
\text { pass or rent a ski house or condo etc.). I will only stop } \\
\text { skiing/snowboarding if I am injured or experience a serious barrier. } \\
\text { I do not think there is any other activity that can replace } \\
\text { skiing/snowboarding. For me, the most important factor in choosing } \\
\text { a ski/snowboard destination are the snow conditions. I am an } \\
\text { intermediate/advanced skier/snowboarder. }\end{array}$ & 319 & 40.3 \\
\hline Total & 792 & 100.0 \\
\hline
\end{tabular}


Table 2.

EI items descriptive statistics

\begin{tabular}{|c|c|c|c|}
\hline Items & $M$ & $S D$ & $N$ \\
\hline Skiing/snowboarding is pleasurable & 5.80 & 1.47 & 793 \\
\hline I really enjoy skiing/snowboarding & 5.71 & 1.55 & 793 \\
\hline Skiing/snowboarding interests me a lot & 5.24 & 1.68 & 793 \\
\hline Skiing/snowboarding provides the chance to socialize with my friends or family & 5.18 & 1.66 & 793 \\
\hline I enjoy discussing skiing/snowboarding with my friends or family & 4.78 & 1.77 & 793 \\
\hline Skiing/snowboarding is one of the most satisfying things I do & 4.65 & 1.83 & 793 \\
\hline Participation in skiing/snowboarding says something about me & 4.65 & 1.76 & 793 \\
\hline Skiing/snowboarding reflects my lifestyle & 4.59 & 1.81 & 793 \\
\hline Other people see an important side of me when I participate in skiing/snowboarding & 4.25 & 1.94 & 793 \\
\hline I attach great importance to skiing/snowboarding & 4.24 & 1.99 & 793 \\
\hline When I participate in skiing/snowboarding, others see me the way I want them to see me & 4.20 & 1.82 & 793 \\
\hline Skiing/snowboarding is an important part of who I am & 4.17 & 1.97 & 793 \\
\hline I can tell things about other people by seeing them participating in skiing/snowboarding & 4.07 & 1.79 & 793 \\
\hline Skiing/snowboarding reflects who I am & 4.05 & 1.92 & 793 \\
\hline I would rather ski/snowboard than do most anything else & 3.95 & 1.90 & 793 \\
\hline Most of my friends or family members are in some way connected to skiing/snowboarding & 3.92 & 1.88 & 793 \\
\hline Skiing/snowboarding has a central role in my life & 3.84 & 1.97 & 793 \\
\hline I find a lot of my life is organized around skiing/snowboarding & 3.64 & 2.04 & 793 \\
\hline
\end{tabular}

Note. All items were measured from strongly disagree (1) to strongly agree (7) 
Table 3.

Destination attributes item descriptive statistics

\begin{tabular}{lccc}
\hline Items & $M$ & $S D$ & $N$ \\
\hline Ski conditions & 5.76 & 1.26 & 673 \\
Total price of the trip & 5.68 & 1.44 & 673 \\
The terrain & 5.43 & 1.35 & 673 \\
Range of slopes & 5.42 & 1.40 & 673 \\
Accommodation price & 5.34 & 1.53 & 673 \\
Lift ticket price & 5.23 & 1.63 & 673 \\
Resort accessibility & 5.22 & 1.54 & 673 \\
Quality of trail grooming & 5.15 & 1.57 & 673 \\
Accommodation quality & 5.01 & 1.59 & 673 \\
Quality of the available food places & 4.43 & 1.65 & 673 \\
Price of the available food places & 4.23 & 1.70 & 673 \\
Opportunity for other outdoor activities & 4.12 & 1.79 & 673 \\
Leisure facilities (e.g. spa, nightlife, etc.) & 3.73 & 1.79 & 673 \\
Sightseeing attractions & 3.65 & 1.78 & 673 \\
Good shopping & 3.01 & 1.77 & 673 \\
\hline Note. All itms
\end{tabular}

Note. All items were measured from not at all important (1) extremely important (7) 
Table 4.

Factor analysis of the Enduring Involvement scale

Varimax-rotated loadings

EI items

Factors

F1

F2

Identity/Centrality Hedonism

Skiing/snowboarding has a central role in my life .868

I find a lot of my life is organized around skiing/snowboarding

Skiing/snowboarding is an important part of who I am

.830

Skiing/snowboarding reflects who I am

I attach great importance to skiing/snowboarding

.793

Other people see an important side of me when I participate in skiing/snowboarding

.764

I would rather ski/snowboard than do most anything else

I can tell things about other people by seeing them participating in skiing/snowboarding

When I participate in skiing/snowboarding, others see me the way I want them to see me

.715

Most of my friends or family members are in some way connected to skiing/snowboarding

.682

Skiing/snowboarding is pleasurable

I really enjoy skiing/snowboarding

Skiing/snowboarding interests me a lot

Skiing/snowboarding provides the chance to socialize with my friends or family

Factor's mean

Eigenvalue

6.59

$\%$ of variance explained

47.06

AVE

.60

.61

Cronbach's Alpha

.95

Note. All items were measured from strongly disagree (1) to strongly agree (7) 
Table 5.

EI of four types of skiers/snowboarders MANOVA

\begin{tabular}{lcccccccccc}
\hline & \multicolumn{2}{c}{ Type 1} & \multicolumn{2}{c}{ Type 2} & \multicolumn{2}{c}{ Type 3 } & \multicolumn{3}{c}{ Type 4} \\
$(n=153)$ & \multicolumn{2}{c}{$(n=225)$} & \multicolumn{2}{c}{$(n=96)$} & \multicolumn{2}{c}{$(n=319)$} & \\
Factor & $M$ & $S D$ & $M$ & $S D$ & $M$ & $S D$ & $M$ & $S D$ & $F(3,789)$ & $P$ \\
\hline Identity/Centrality & 2.57 & 1.46 & 3.46 & 1.21 & 3.94 & 1.25 & 5.16 & 1.24 & 163.154 & .000 \\
Hedonism & 4.21 & 1.49 & 5.18 & 1.13 & 5.40 & 1.04 & 6.32 & 0.83 & 135.544 & .000 \\
\hline
\end{tabular}

Note. Pillai's Trace $=.43, F(6,1576)=72.041, p<.05$. Items were measured from $1=$ strongly disagree to $7=$ strongly agree. 
Table 6.

$\underline{\text { Post hoc analyses of pairwise comparisons Bonferroni }}$

\begin{tabular}{|c|c|c|c|c|}
\hline Factor & Type (I) & Type (J) & $\begin{array}{c}\text { Mean Difference } \\
(\mathrm{I}-\mathrm{J})\end{array}$ & $P$ \\
\hline \multirow[t]{4}{*}{ Identity/Centrality } & $\begin{array}{c}1 \\
\text { (initiation stage) }\end{array}$ & $\begin{array}{l}2 \\
3 \\
4\end{array}$ & $\begin{array}{l}-0.89 \\
-1.37 \\
-2.59\end{array}$ & $\begin{array}{l}.000 \\
.000 \\
.000\end{array}$ \\
\hline & $\begin{array}{c}2 \\
\text { (attachment stage) }\end{array}$ & $\begin{array}{l}1 \\
3 \\
4\end{array}$ & $\begin{array}{c}0.89 \\
-0.48 \\
-1.70\end{array}$ & $\begin{array}{l}.000 \\
.013 \\
.000\end{array}$ \\
\hline & $\begin{array}{c}3 \\
\text { (attachment stage) }\end{array}$ & $\begin{array}{l}1 \\
2 \\
4\end{array}$ & $\begin{array}{r}1.37 \\
0.48 \\
-1.22\end{array}$ & $\begin{array}{l}.000 \\
.013 \\
.000\end{array}$ \\
\hline & $\begin{array}{c}4 \\
\text { (commitment stage) }\end{array}$ & $\begin{array}{l}1 \\
2 \\
3\end{array}$ & $\begin{array}{l}2.59 \\
1.70 \\
1.22\end{array}$ & $\begin{array}{l}.000 \\
.000 \\
.000\end{array}$ \\
\hline \multirow[t]{4}{*}{ Hedonism } & $\begin{array}{c}1 \\
\text { (initiation stage) }\end{array}$ & $\begin{array}{l}2 \\
3 \\
4\end{array}$ & $\begin{array}{l}-0.97 \\
-1.19 \\
-2.11\end{array}$ & $\begin{array}{l}.000 \\
.000 \\
.000\end{array}$ \\
\hline & $\begin{array}{c}2 \\
\text { (attachment stage) }\end{array}$ & $\begin{array}{l}1 \\
3 \\
4\end{array}$ & $\begin{array}{c}0.97 \\
-0.22 \\
-1.13\end{array}$ & $\begin{array}{l}.000 \\
.579 \\
.000\end{array}$ \\
\hline & $\begin{array}{c}3 \\
\text { (attachment stage) }\end{array}$ & $\begin{array}{l}1 \\
2 \\
4\end{array}$ & $\begin{array}{c}1.19 \\
0.22 \\
-0.91\end{array}$ & $\begin{array}{l}.000 \\
.579 \\
.000\end{array}$ \\
\hline & $\begin{array}{c}4 \\
\text { (commitment stage) }\end{array}$ & $\begin{array}{l}1 \\
2 \\
3\end{array}$ & $\begin{array}{l}2.11 \\
1.13 \\
0.91\end{array}$ & $\begin{array}{l}.000 \\
.000 \\
.000\end{array}$ \\
\hline
\end{tabular}

Note. The mean difference is significant at the 0.05 level 
Table 7.

Factor analysis of the destination attributes items

\begin{tabular}{|c|c|c|c|}
\hline \multirow{3}{*}{ Destination attributes } & \multicolumn{3}{|c|}{ Varimax-rotated loadings } \\
\hline & & Factors & \\
\hline & $\begin{array}{c}\text { F1 } \\
\text { Resort } \\
\text { amenities and } \\
\text { activities }\end{array}$ & $\begin{array}{c}\text { F2 } \\
\text { Snow sport } \\
\text { conditions and } \\
\text { quality }\end{array}$ & $\begin{array}{c}\text { F3 } \\
\text { Price }\end{array}$ \\
\hline Sightseeing attractions & .857 & & \\
\hline Good shopping & .827 & & \\
\hline Leisure facilities (e.g. spa, nightlife, etc.) & .813 & & \\
\hline Opportunity for other outdoor activities & .759 & & \\
\hline Quality of the available food places & 630 & & \\
\hline Price of the available food places & .603 & & \\
\hline The terrain & & .871 & \\
\hline Range of slopes & & .852 & \\
\hline Ski conditions & & .751 & \\
\hline Quality of trail grooming & & .668 & \\
\hline Total price of the trip & & & .841 \\
\hline Lift ticket price & & & .834 \\
\hline Accommodation price & & & .822 \\
\hline Factor's mean & 3.86 & 5.43 & 5.41 \\
\hline Eigenvalue & 3.53 & 2.66 & 2.44 \\
\hline$\%$ of variance explained & 27.2 & 20.48 & 18.87 \\
\hline AVE & .56 & .62 & .69 \\
\hline Cronbach's Alpha & .86 & .81 & .83 \\
\hline
\end{tabular}

Note. All items were measured from strongly disagree (1) to strongly agree (7) 
Table 8.

Importance of destination attributes' dimensions for four types of skiers/snowboarders ANOVA

\begin{tabular}{|c|c|c|c|c|c|c|c|c|c|c|c|c|}
\hline \multirow[b]{2}{*}{ Factor } & \multicolumn{2}{|c|}{$\begin{array}{c}\text { Type } 1 \\
(n=97)\end{array}$} & \multicolumn{2}{|c|}{$\begin{array}{c}\text { Type } 2 \\
(n=186)\end{array}$} & \multicolumn{2}{|c|}{$\begin{array}{c}\text { Type } 3 \\
(n=79)\end{array}$} & \multicolumn{2}{|c|}{$\begin{array}{c}\text { Type } 4 \\
(n=190)\end{array}$} & \multirow[b]{2}{*}{$\begin{array}{c}\text { Between } \\
\text { Group } \\
d f\end{array}$} & \multirow[b]{2}{*}{$\begin{array}{l}\text { Within } \\
\text { Group } \\
\quad d f\end{array}$} & \multirow[b]{2}{*}{$F$} & \multirow[b]{2}{*}{$P$} \\
\hline & $M$ & $S D$ & $M$ & $S D$ & $M$ & $S D$ & $M$ & $S D$ & & & & \\
\hline Resort amenities & 4.29 & 1.30 & 4.27 & 1.33 & 3.87 & 1.42 & 3.51 & 1.23 & 3 & 548 & 13.26 & .000 \\
\hline Snow sport quality & 4.97 & 1.34 & 5.40 & 1.09 & 5.37 & 1.02 & 5.64 & 1.00 & 3 & 547 & 7.79 & .000 \\
\hline Price & 5.55 & 1.17 & 5.48 & 1.28 & 5.50 & 1.17 & 5.32 & 1.38 & 3 & 547 & 0.88 & .447 \\
\hline
\end{tabular}

Note. $p<.05$ 
Table 9.

Post hoc analyses of pairwise comparisons Bonferroni

\begin{tabular}{|c|c|c|c|c|}
\hline Factor & $\begin{array}{c}\text { Type of } \\
\text { skier/snowboarder } \\
\text { (I) }\end{array}$ & $\begin{array}{c}\text { Type of } \\
\text { skier/snowboarder } \\
(\mathrm{J})\end{array}$ & $\begin{array}{c}\text { Mean } \\
\text { Difference } \\
(\mathrm{I}-\mathrm{J}) \\
\end{array}$ & $p$ \\
\hline \multirow{12}{*}{$\begin{array}{l}\text { Resort amenities and } \\
\text { activities }\end{array}$} & Type 1 & Type 2 & 0.023 & 1.000 \\
\hline & (initiation stage) & Type 3 & 0.419 & .211 \\
\hline & & Type 4 & $0.787 *$ & .000 \\
\hline & Type 2 & Type 1 & -0.023 & 1.000 \\
\hline & (attachment stage) & Type 3 & 0.395 & .150 \\
\hline & & Type 4 & $0.763 *$ & .000 \\
\hline & Type 3 & Type 1 & -0.419 & .211 \\
\hline & (attachment stage) & Type 2 & -0.395 & .150 \\
\hline & & Type 4 & 0.367 & .218 \\
\hline & Type 4 & Type 1 & -0.787 & .000 \\
\hline & (commitment stage) & Type 2 & $-0.763 *$ & .000 \\
\hline & & Type 3 & -0.367 & .218 \\
\hline \multirow{12}{*}{$\begin{array}{l}\text { Snow sport conditions } \\
\text { and quality }\end{array}$} & Type 1 & Type 2 & $-0.431^{*}$ & .012 \\
\hline & (initiation stage) & Type 3 & -0.399 & .106 \\
\hline & & Type 4 & $-0.667^{*}$ & .000 \\
\hline & Type 2 & Type 1 & $0.431^{*}$ & .012 \\
\hline & (attachment stage) & Type 3 & 0.032 & 1.000 \\
\hline & & Type 4 & -0.235 & .239 \\
\hline & Type 3 & Type 1 & 0.399 & .106 \\
\hline & (attachment stage) & Type 2 & -0.032 & 1.000 \\
\hline & & Type 4 & -0.268 & .427 \\
\hline & Type 4 & Type 1 & $0.667^{*}$ & .000 \\
\hline & (commitment stage) & Type 2 & 0.235 & .239 \\
\hline & & Type 3 & 0.268 & .427 \\
\hline
\end{tabular}

*Note. The mean difference is significant at the 0.05 level 